\begin{tabular}{|c|l|}
\hline Title & $\begin{array}{l}\text { Introgression and Habitat Segregation in a Pair of Lady bird Beetle Species in the Genus Propylea (Coccinellidae, } \\
\text { Coccinellinae) in Northern Japan }\end{array}$ \\
\hline Author(s) & Suga, Hiromu; Hirano, Wataru; Katoh, Toru; Matsubay ashi, Kei W.; Katakura, Haruo \\
\hline Citation & $\begin{array}{l}\text { Zoological science, 33(6), 603-610 } \\
\text { https://loi.org/10.2108/2s160062 }\end{array}$ \\
\hline Issue Date & 2016-12 \\
\hline Doc URL & http://hdl.handle.net/2115/67769 \\
\hline Type & article \\
\hline File Information & Zs33603-610.pdf \\
\hline
\end{tabular}

Instructions for use 


\title{
Introgression and Habitat Segregation in a Pair of Ladybird Beetle Species in the Genus Propylea (Coccinellidae, Coccinellinae) in Northern Japan
}

\author{
Hiromu Suga ${ }^{1}$, Wataru Hirano ${ }^{1}$, Toru Katoh ${ }^{1 *}$, Kei W. Matsubayashi ${ }^{2}$, \\ and Haruo Katakura ${ }^{1,3}$ \\ ${ }^{1}$ Department of Biological Sciences, Faculty of Science, Hokkaido University, Sapporo 060-0810, Japan \\ ${ }^{2}$ The Faculty of Arts and Science, Kyushu University, Fukuoka 819-0395, Japan \\ ${ }^{3}$ The Hokkaido University Museum, Hokkaido University, Sapporo 060-0810, Japan
}

\begin{abstract}
The ladybird beetles Propylea quatuordecimpunctata and $P$. japonica have largely overlapping distributions in northern Japan, and in the laboratory produce fertile hybrids. In this study, we surveyed the distribution and morphological differentiation of these species and the hybrids in natural populations, with a focus on western Hokkaido, northern Japan. Phenotypic analyses were conducted for 987 individuals collected at 90 localities. In addition, the nuclear internal transcribed spacer-II (ITS2) region (549 bp) and part of the mitochondrial cytochrome c oxidase subunit I (COI) gene (700 bp) were sequenced for 620 individuals from 53 localities. Analyses of both phenotypic and genotypic features discriminated two distinct entities assignable to $P$. quatuordecimpunctata and $P$. japonica. However, individuals with intermediate phenotypes and/or genotypes also occurred extensively, indicating natural hybridization. Putative $P$. quatuordecimpunctata individuals were collected across a wide range of altitudes $(30-600 \mathrm{~m})$, whereas those of $P$. japonica were found mostly lower than $300 \mathrm{~m}$ alt. In addition, $P$. quatuordecimpunctata was dominant in semi-open habitats shaded by canopy foliage, whereas $P$. japonica was frequent in more open habitats. The perceived altitudinal difference in the distributions may thus in part be a consequence of this different habitat preference, as open habitats are more common at lower altitudes in the study area.
\end{abstract}

Key words: canopy openness, differentiation, distribution, ladybird beetle, natural hybridization, reproductive isolation

\section{INTRODUCTION}

Species are biological entities differentiated from other such entities by morphological, ecological, and genetic traits. In biparentally reproducing organisms, species are usually reproductively isolated from each other by various sorts of barriers (cf. Futuyma, 2013). Hence, study of the means by which reproductive barriers are formed and maintained is crucial for understanding the nature of species and speciation (Coyne and Orr, 1998; Levin, 2000; Wu, 2001). In contrast, natural hybridization has also been documented between distinct biological entities assignable to separate species (Crow et al., 2007; de Casas et al., 2007; Yatabe et al., 2007). Detailed analyses of such incompletely reproductively isolated species have contributed to a better understanding of species boundaries, and the evolution and maintenance of reproductive barriers (Coyne and Orr, 2004).

Propylea quatuordecimpunctata (Linnaeus) and $P$. japonica (Thunberg) are predaceous ladybird beetles that

\footnotetext{
* Corresponding author. Tel. : : +81-11-706-3581;

Fax : +81-11-726-3476;

E-mail: tkatoh@mail.sci.hokudai.ac.jp
}

Supplemental material for this article is available online.

doi:10.2108/zs160062 feed primarily on aphids and are common in various environments, including orchards, forest margin, grasslands, and crop fields (Hukushima and Komada, 1971; Kawauchi, 1997; Honěk, 2012). In Japan, $P$. japonica spends multiple generations in a year and hibernates as adults (Hukushima and Komada, 1971; Kawauchi, 1997). Although we did not find relevant publications for Japanese $P$. quatuordecimpunctata, it must be also multivoltine, at least in warmer areas, and hibernates as an adult. The two species are very similar in external appearance and biology, and their identity was in question until $\mathrm{H}$. Sasaji and co-workers conducted detailed analyses of their morphology and distribution, and performed crossing experiments (reviewed in Sasaji, 1998). The two species are distinguishable by slight but rather stable differences in many morphological characters, particularly the elytral spot pattern, melanization of legs and abdomens, and minute structures in the male genitalia (Sasaji et al., 1975). Propylea quatuordecimpunctata is widely distributed in the Palearctic region (and now introduced in North America), whereas $P$. japonica inhabits eastern Asia. In Japan, the former is distributed in the north (Hokkaido and the northern half of Honshu), and the latter across the entire country, including the Ryukyu Islands. In the zone of overlap, the two species are often found in the same locality, although they differ in altitudinal distribution, with $P$. japonica tending 
to live at lower altitudes (Sasaji et al., 1975). In the laboratory, the two species produce fertile $F_{1}$ hybrids of both sexes, but successive hybrid crossings lead to the demise of the population (Sasaji et al., 1975). Furthermore, males of both species tend to choose conspecific females as mates when they are given a choice between conspecific and heterospecific females (Sajima and Sasaji, 1988), and males of $P$. japonica are more selective than those of $P$. quatuordecimpunctata. Putative hybrids of intermediate phenotype were hardly found in the wild (Sasaji et al., 1975; Sasaji, 1998). On the basis of these findings, Sasaji and co-workers concluded that $P$. quatuordecimpunctata and $P$. japonica are distinct species that are essentially reproductively isolated from each other in the wild (Sasaji et al., 1975; Sasaji, 1998).

No study has been made on the relationships of the two Japanese Propylea species after Sasaji et al. (1975) and Sajima and Sasaji (1988), although there are a number of publications regarding the biology of Propylea beetles (Pervez and Omkar, 2011; Hodek et al., 2012) studied from the perspective of an potential application, i.e., Propylea species as biocontrol agents of crop pests. The ecological traits of these aphidophagous beetles, which may be responsible for their reproductive isolation, are poorly known. Moreover, no attempt has been made to detect natural hybridization based on molecular markers. It is therefore unclear whether the two species are fully reproductively isolated when they occur sympatrically. To answer to this question, we analyzed hybrids in natural populations of the two species in the zone of overlap in western Hokkaido, northern Japan, using both external phenotypic features and DNA markers.

\section{MATERIALS AND METHODS}

\section{Sampling}

Propylea beetles were sampled from 2007 to 2011 in western Hokkaido and other areas in Japan. We collected 972 adult individuals (887 individuals from Hokkaido and 85 individuals from Honshu) at 88 sites (74 sites on Hokkaido, 14 sites on Honshu) by sweeping and hand sampling (Supplementary Table S1 online, Fig. 1). Our study included these specimens and 15 individuals from two localities in Europe. Specimens were fixed and preserved in $99 \%$ ethanol until analysis. The position of each sampling site in Japan was determined by using GPS or Google Maps, and the vegetation type and other habitat characteristics were recorded. In the course of beetle sampling, we noted possible differences in preferred habitat between the two Propylea species; $P$. japonica tended to be found in more open environments than $P$. quatuordecimpunctata. Since such a difference would potentially be important for the co-occurrence and reproductive isolation of the two species, we additionally estimated the canopy openness (COP; the proportion of the area not covered by canopy in a hemispherical photo) for 19 sites in Hokkaido in the last year of the field study (2011). Photos were taken in July and August using a digital camera (Polaroid $t$ 1235) equipped with a fisheye lens (T-03L; DIGITAL KING) set $2 \mathrm{~m}$ above the ground, and were analyzed with CanopOn2 (Takenaka, 2009).

\section{Scoring of external characters}

For all specimens, the following external characters were examined according to the diagnoses of Sasaji et al. (1975).

1) Elytral maculation: Elytral maculation of the Propylea beetles is highly variable, and Sasaji et al. (1975) illustrated 16 different patterns for Japanese forms of $P$. quatuordecimpunctata and 13 patterns for those of $P$. japonica. Representative patterns found in the present study are given in Fig. $1(a-f)$. Some patterns are found only in one species (e.g., two-spotted form of $P$. japonica shown in Fig. 1a). However, most of the specimens have elytron with multiple black spots of various sizes in addition to the sutural black stripe (Fig. 1b-f). The reliable diagnosis for these specimens is the condition of the spot(s) on the humeral region. There is only one spot on the humeral region in $P$. japonica (Fig. $1 \mathrm{~b}, \mathrm{c}$ ), while two spots are clearly recognizable in $P$. quatuordecimpunctata, although these may be separate (Fig. 1f) or fused together (Fig. 1e). We treated the pattern as intermediate when the number of humeral spots was difficult to judge (Fig. 1d).

2) Abdominal melanization: The abdominal sternum is broadly black at the middle and yellowish or brownish laterally. The boundary of medial black area and lateral pale area is well defined and nearly straight in $P$. japonica (Fig. $1 \mathrm{~g}$ ). In $P$. quatuordecimpunctata, the black area of each segment strongly extends laterally in the

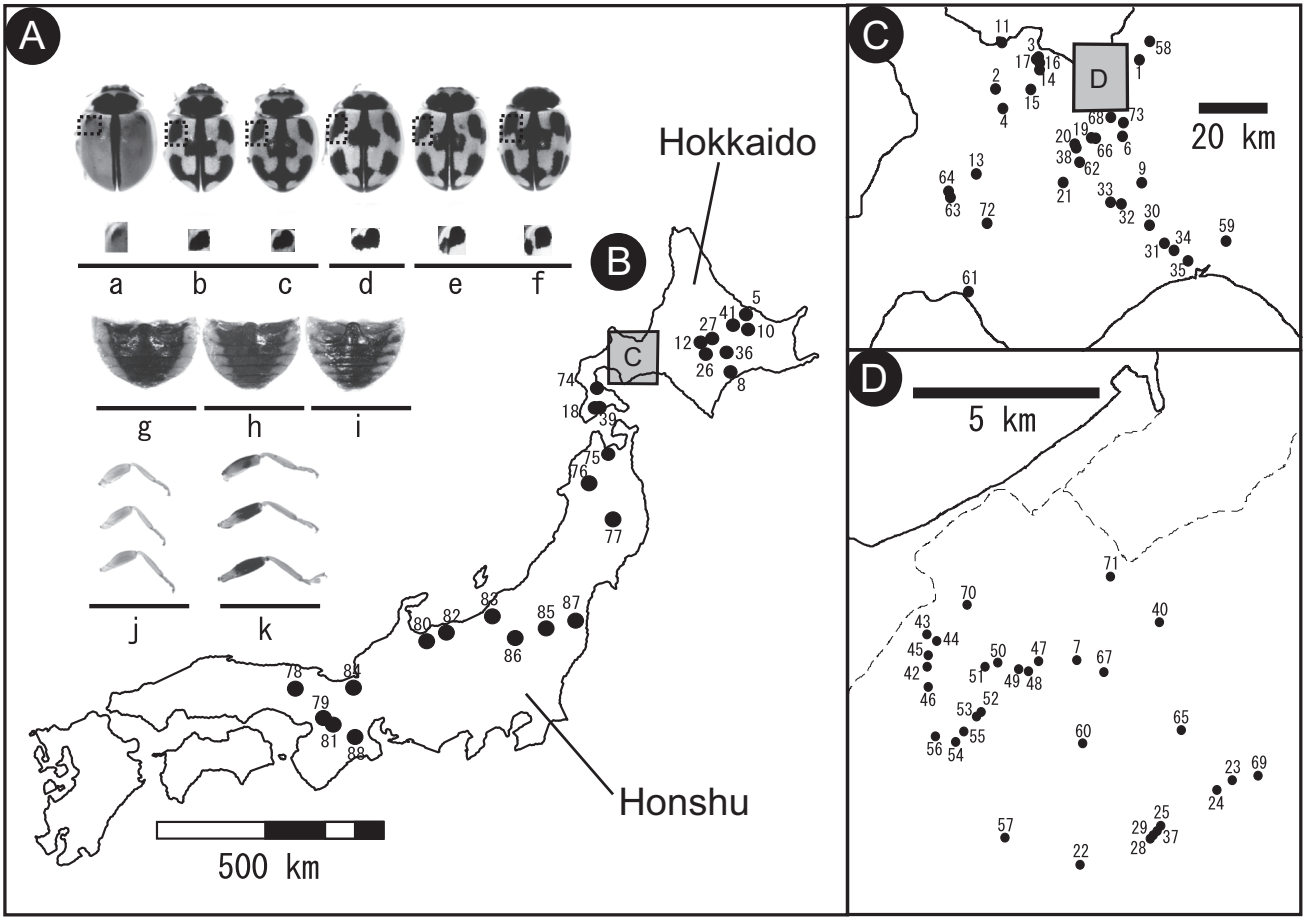

Fig. 1. Phenotypic characters (A) and sampling localities for Propylea japonica and P. quatuordecim punctata (B-D). Phenotypic characters (A): elytral spot patterns $(a-f)$, below which are oblique views of the left humeral spots; abdominal melanization ( $\mathrm{g}-\mathrm{i})$; leg melanization $(\mathrm{j}, \mathrm{k}$; fore-, mid- and hind-leg from the top). Characters a-c, g, j correspond to $P$. japonica; e, f, i, k correspond to $P$. quatuordecimpunctata; $\mathrm{d}, \mathrm{h}$ are intermediate (after Sasaji et al., 1975). Population numbers are as in Supplementary Table S1. 
posterior part of the segment and nearly reaches the lateral margin (Fig. 1i). We treated the pattern as intermediate when the lateral extension of black area was weak (Fig. 1h).

3) Leg coloration: Legs are totally yellowish brown except for blackish coxae in P. japonica (Fig. 1j, coxa is not shown), whereas the middle part of femora and the posterior margin of trochanters are black in $P$. quatuordecimpunctata (Fig. 1k). No intermediate conditions were recognized in leg coloration.

Character states considered inherent to $P$. japonica (Fig. 1a-c, $\mathrm{g}$, j) were rated 0 , those inherent to $P$. quatuordecimpunctata (Fig. $1 \mathrm{e}, \mathrm{f}, \mathrm{i}, \mathrm{k}$ ) were rated 2 , and intermediate states (Fig. 1d, h) were rated 1. The scores for the three characters were summed for each individual to give the phenotypic index $(\mathrm{PI})$, which ranged in value from 0 to 6 (denoted $\mathrm{PI}-0$ to $\mathrm{PI}-6$ ).

\section{DNA extraction, PCR amplification, and sequencing}

Genomic DNA was extracted from three legs of each specimen by using the silica method of Boom et al. (1990), with some modifications. Extracted DNA was dissolved in $20 \mu \mathrm{l}$ of TE buffer $(10 \mathrm{mM}$ Tris- $\mathrm{HCl}, \mathrm{pH}$ 8.0; $0.1 \mathrm{mM}$ EDTA) and the solution was stored at $-20^{\circ} \mathrm{C}$. PCR amplification of the $\mathrm{CO} /$ region was performed with the primers UEAM5-mod (5'-AGTTTTAGCAGGAGCAATTAC- $\left.3^{\prime}\right)$ and UEAM10-mod (5'-TGCACTAATCTGCCATATTA-3'), modified from primers UEAM5 and UEAM10, respectively, in Lunt et al. (1996). PCR amplification of the ITS2 region was performed with primers ITS3f (5'-GCATCGATGAAGAACGCAGC-3') and ITS3r (5'TCCTCCGCTTATTGATAT-GC-3') (White et al., 1990). Amplifications were carried out in an iCycler (Bio-Rad Laboratories) in 10- $\mu \mathrm{l}$ reaction volumes, each containing $1 \times$ Ex Taq buffer (Takara Bio), 200 $\mu \mathrm{M}$ each dNTP, $0.5 \mu \mathrm{M}$ each primer, $0.25 \mathrm{U}$ Ex Taq polymerase (Takara Bio), and $0.5 \mu \mathrm{l}$ template DNA solution. PCR cycling conditions for both genes were $95^{\circ} \mathrm{C}$ for $3 \mathrm{~min}$; 35 cycles of $95^{\circ} \mathrm{C}$ for 30 $\mathrm{s}, 40^{\circ} \mathrm{C}$ for $90 \mathrm{~s}$, and $72^{\circ} \mathrm{C}$ for $90 \mathrm{~s}$; and $72^{\circ} \mathrm{C}$ for $7 \mathrm{~min}$. PCR products were purified with the silica method noted above, and directly sequenced in both directions using a BigDye Terminator Sequencing Kit and an ABI 3100-Avant or 3730 Genetic Analyzer (Life Technologies), following the manufacturers' protocols.

Haplotypes for the ITS2 sequences that included heterozygous indels, which were distinguished by the presence of many double peaks in the chromatogram, were determined by assessing the chromatogram patterns sequenced from both directions (Supplementary Figure S1 online). Haplotypes for the ITS sequences without heterozygous indels were unambiguously determined, because these sequences had no double heterozygote sites.

\section{Analyses of haplotype relationships}

The nucleotide sequences obtained were aligned by using the ClustalW algorithm (Thompson et al., 1994) implemented in MEGA5 software (Tamura et al., 2011) at default settings. The resulting alignments were checked by eye. DNASP 5.10 .01 (Librado and Lozas, 2009) was used to search the sequences for haplotype variation. A median-joining (MJ) network (Bandelt et al., 1999) was constructed to describe the relationships among haplotypes, using NETWORK 4.6.1.3 (http://www.fluxus-engineering.com) at default settings.

Divergence times for the $\mathrm{CO}$ / haplotypes were estimated using BEAST 1.8.2 (Drummond et al., 2012), together with the BEAGLE library (Ayres et al., 2011) for multicore processing. The alignment sequences were partitioned by codon positions (1st, 2nd, and 3rd), and the evolutionary model of nucleotide substitutions for each data partition was selected based on the Akaike information criterion (AIC) implemented in MrModeltest 2.3 (Nylander, 2004), together with PAUP* $4.0 \mathrm{~b} 10$ (Swofford, 2003). A strict clock was selected for the clock model, and the constant coalescent process was selected for the tree prior model. The clock rate was set to $3.54 \%$ divergence per million years (Papadopoulou et al., 2010). A Markov-Chain Monte-Carlo (MCMC) search was run for 10 million generations starting with a random tree, in which trees were sampled every 1000 generations. The first 1000 samples were discarded as burnin, and the maximum clade credibility (MCC) tree was generated using TreeAnnotator 1.8.2 (Drummond et al., 2012). Tracer 1.6.0 (Rambaut et al., 2014) was used to confirm that all effective sample sizes (ESS) were enough for reliable parameter estimates.

\section{Analyses of phenotypic indices and genotypes}

To test the relationship between morphological characters and genotypes, we applied generalized liner model (GLM) with R 3.1.2 statistical software (R Developmental Core Team, 2014) using Poisson probability distributions. We tested the effect of the two explanatory variables "mitochondria haplotype group" (including 2 classes) and "ITS genotype" (including 3 classes) on a response variable "phenotypic index" (including 7 classes, 0 to 6 ) independently.

\section{Analyses of the effect of altitude and canopy openness on bee- tle occurrence}

The effect of altitude and canopy openness (COP) to phenotypic index, mitochondrial haplotype group, and ITS genotype were tested with the generalized linear mixed model (GLMM). This analysis included 19 populations in the vicinity of Sapporo for which both altitude and COP data were available (see Supplementary Table S1 online). We set two main explanatory variables ("Altitude" and "COP"), the interaction "Altitude $\times$ COP", and three response variables ("phenotypic index", "mitochondrial haplotype group", and "ITS genotype") with setting "population" as a random effect. We applied a hierarchical Bayes model of MCMC glmm package with $\mathrm{R}$ 3.1.2 statistical software using Poisson probability distributions for "phenotypic index" and for "ITS genotype", and binomial probability distribution for "mitochondrial haplotype group". The best model was selected by comparing the deviance information criteria (DIC) for all the models throughout full model with three factors to null model with no factor. The number of Markov chain iterations was 13,000 , with 3000 burn-in. For example, full model description for phenotypic group is "Phenotype index Altitude + COP + Altitude * COP". For a more rigorous test for the effect of altitude to these three response variables with sufficient number of sample sizes, we also applied MCMCglmm using all 49 populations collected in Hokkaido for which phenotypic and genetic data were available. Here, we tested only "Altitude" as an explanatory variable, and the other settings were same with the MCMCgImm methods described above.

\section{RESULTS}

\section{Phenotypic index}

The distribution of the phenotypic index of all individuals examined had two peaks, a moderate peak at PI-0 (all features typical for $P$. japonica) and a higher one at PI-6 (all features typical for $P$. quatuordecimpunctata), with the lowest frequency at PI-4 (Fig. 2). The Hokkaido samples included individuals in all seven PI groups (Supplementary Table S1 online). In contrast, individuals in the Honshu samples were mostly $\mathrm{PI}-0$ to $\mathrm{PI}-2$, with only one individual showing PI-6, and no PI-3 to PI-5 individuals. The two European samples were composed exclusively of PI-6 individuals.

On Hokkaido, both the light and dark forms were widely distributed and broadly sympatric (Supplementary Table S1 online). For example, the two lightest forms (PI-0 and $\mathrm{PI}-1)$ were collected at 37 sites $(50.0 \%)$, ranging from 3 to $770 \mathrm{~m}$ alt., and the two darkest forms (PI-5 and PI-6) at 55 sites (74.3\%), ranging from 6 to $842 \mathrm{~m}$ alt., among the 74 sites in Hokkaido. The light and dark forms were found together at 19 sites (35.2\%). 


\section{Haplotypes and haplotype relationships}

We obtained nucleotide sequences of part of the mitochondrial $\mathrm{COI}$ gene (700 bp) and the nuclear ITS2 region (549 bp) for 620 individuals from 51 sampling sites (Tables S1, S2). All haplotype sequences have been deposited in the DDBJ/EMBL/GenBank database under accession numbers LC054059-LC054162.

COI: An alignment of $\mathrm{COI}$ sequences detected 48 haplotypes and 50 substitution sites (of which 47 were synonymous), with no alignment gaps. Of the 48 haplotypes, 29 were unique to single sampling sites, five were shared by Hokkaido and Honshu populations, and three were shared by Japanese and European populations (Supplementary Table S2 online). A haplotype network constructed with the MJ method (Fig. 3, COI) shows two lineages differentiated by 20 nucleotide substitutions, designated as groups $\alpha$ and $\beta$. Group $\alpha$ showed high genetic diversity. Both haplotype groups were represented in samples from Hokkaido and Honshu, but only $\alpha$ haplotypes were detected in European samples (Supplementary Table S2 online). Divergence time between the two haplotype groups was estimated at 1.6 Mya (95\% HPD = 1.0-2.2 Mya; Supplementary Figure S2 online), which does not deviate significantly from the mean speciation time ( 2 Mya) inferred based on the concatenated timetree of many animals and plants (Hedges et al., 2015).

On Hokkaido, $\alpha$ haplotypes were detected at 43 sites $(87.8 \%, 3$ to $599 \mathrm{~m}$ alt.) and $\beta$ haplotypes at 37 sites $(75.5 \%, 6$ to $599 \mathrm{~m})$, with sympatric occurrence at 31 sites $(N=49)$ (Supplementary Tables S1 and S2 online).

ITS2: An alignment of ITS2 sequences detected 56 haplotypes and 51 substitution sites, with two indel sites. Of these haplotypes, 33 were unique to single sites, four were shared by Hokkaido and Honshu populations, and one was shared by Japanese and European populations (Table S2). A network of ITS2 haplotypes showed two distinct lineages differentiated by five nucleotide substitutions, designated as groups A and B (Fig. 3, ITS2). Groups A and B both show a star topology, with haplotypes A01 and B01 occupying the center, respectively. Both haplotype groups were represented in Hokkaido and
Honshu populations, but only B haplotypes were detected in European populations (Supplementary Table S2 online).

On Hokkaido, A haplotypes were detected at 30 sites

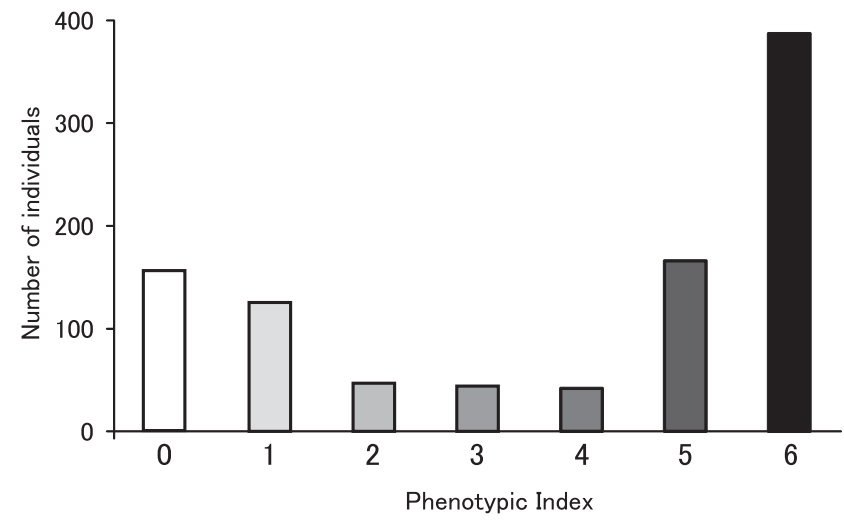

Fig. 2. Values of the phenotypic index estimated from three morphological characters for all individuals. A phenotypic index (PI) value of 0 indicates that all three characters of the individual are in the P. japonica states, as defined in the text (also cf. Fig. 1); PI value of 6 indicates these are in $P$. quatuordecimpunctata states.

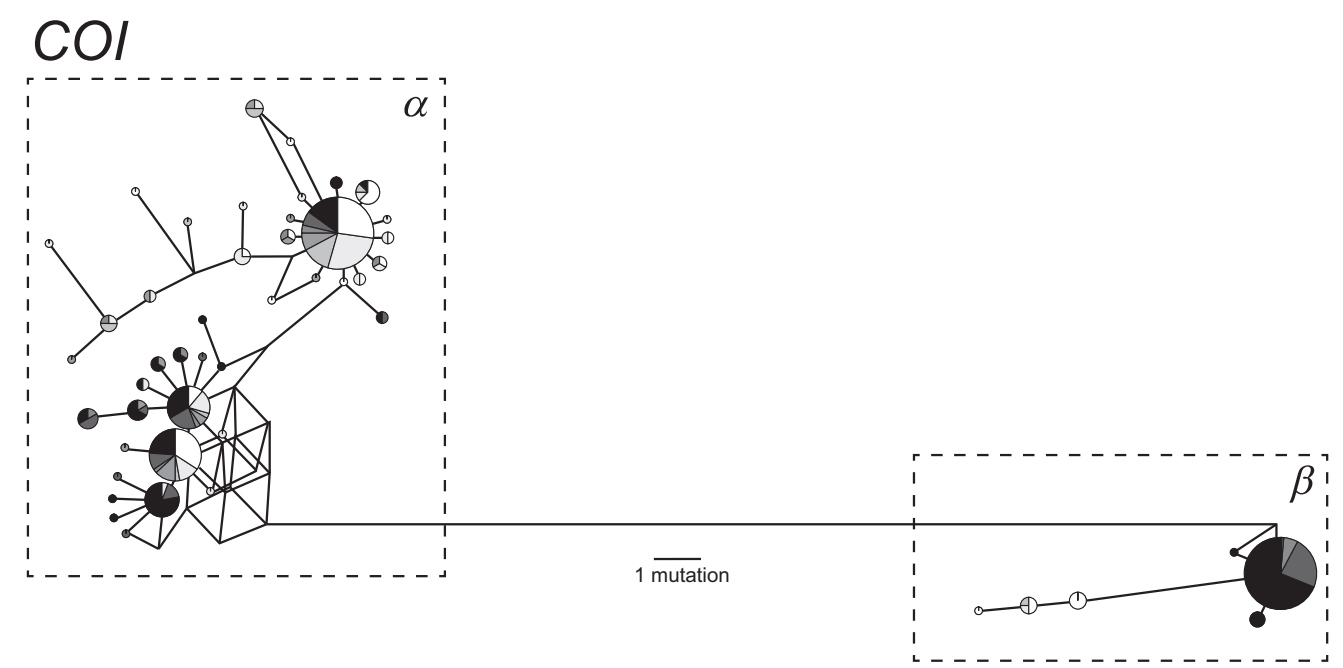

ITS2

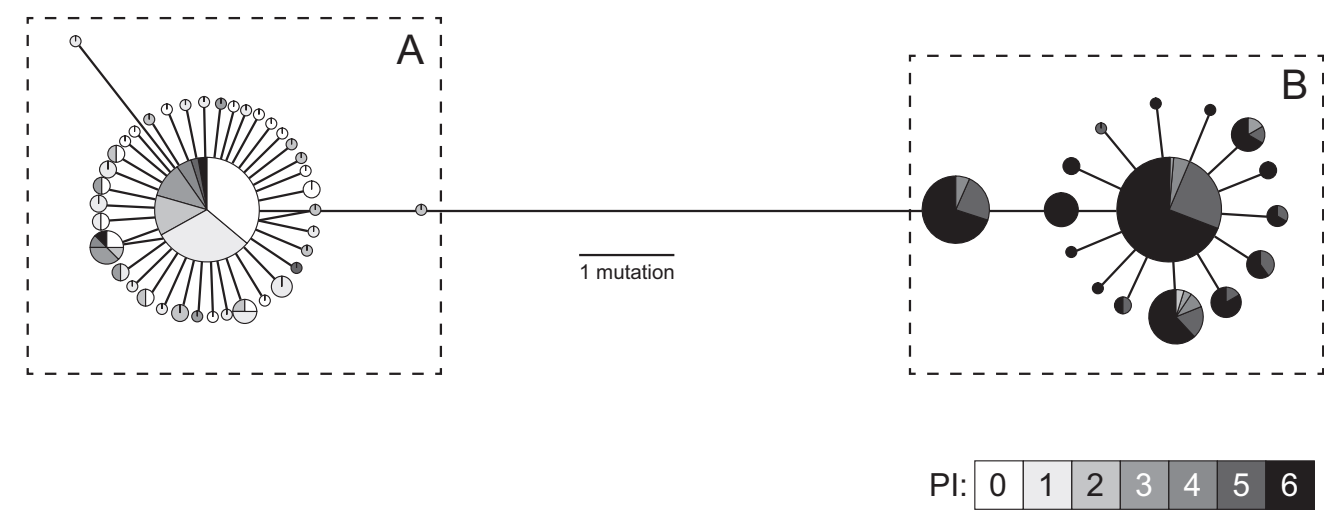

Fig. 3. Haplotype networks constructed by the MJ method for $\mathrm{COI}$ and ITS2 sequences. The phenotypic index $(\mathrm{PI})$ values are indicated by different shading. The size of each pie graph is proportional to the sample size. 
$(61.2 \%, 3$ to $576 \mathrm{~m}$ alt.) and B haplotypes at 40 sites $(81.6 \%, 6$ to $599 \mathrm{~m})$, with sympatric occurrence at 21 sites $(N=49)$ (Supplementary Tables S1 and S2 online).

\section{Genotypes}

Table 1 shows the distribution of individuals classified according to the six genotypes derived from the combination of ITS2 genotypes (AA, $A B, B B)$ and $C O I$ haplotype groups $(\alpha, \beta)$. The ITS2 genotype for each individual was unambiguously identified, as the $A$ and $B$ haplotypes differed by a continuous gap with two indel sites. Most individuals were either $\mathrm{AA} \alpha(38.5 \%)$ or $\mathrm{BB} \beta(37.9 \%)$, with a smaller proportion of $\mathrm{BB} \alpha(16.9 \%)$. The genotype composition was different among Hokkaido, Honshu, and Europe. All six genotypes were detected in Hokkaido samples, whereas only three genotypes ( $\mathrm{AA} \alpha, \mathrm{AA} \beta$, and $\mathrm{BB} \alpha$ ) were detected in Honshu samples. Notably, group $\beta$ haplotypes were in most cases combined with the BB genotype in Hokkaido beetles, whereas they were combined with the AA genotype in Honshu beetles. The seven European specimens invariably had the $\mathrm{BB} \alpha$ genotype.

\section{Phenotypic indices and genotypes}

The distribution of genotypes along the phenotype gradient is shown in Table 2. All the European specimens had the same phenotype/genotype composition (PI-6, BB $\alpha$ ). Honshu specimens were $\mathrm{PI}-0$ to $\mathrm{PI}-2$ with $\mathrm{AA} \alpha \alpha \beta$, except for a single individual of phenotype $\mathrm{PI}-6$ and genotype $\mathrm{BB} \alpha$. In contrast, the Hokkaido specimens were diverse in phenotypic and genotypic composition, with all seven phenotypic and six genotypic classes represented (Table 2). There was a clear relationship between phenotypic index and genotype

Table 1. Distribution of 613 Japanese individuals according to the combination of ITS2 genotypes (AA, $\mathrm{AB}, \mathrm{BB})$ and $\mathrm{CO}$ / haplotype groups $(\alpha, \beta)$. All the seven European individuals possessed $\mathrm{AA} \beta$ genotypes.

\begin{tabular}{crrr}
\hline \multirow{2}{*}{ COI } & \multicolumn{3}{c}{ ITS2 } \\
\cline { 2 - 4 } & $\mathrm{AA}$ & $\mathrm{AB}$ & $\mathrm{BB}$ \\
\hline Hokkaido & & 19 & 97 \\
$\alpha$ & 214 & 10 & 235 \\
$\beta$ & 5 & & \\
\hline Honshu & & 0 & 1 \\
$\alpha$ & 25 & 0 & 0 \\
$\beta$ & 7 & & \\
\hline
\end{tabular}

Table 2. Distribution of 580 Hokkaido individuals classified in seven phenotypic groups and six genotypes.

\begin{tabular}{crrrrrrr}
\hline \multirow{2}{*}{$\begin{array}{c}\text { Phenotypic } \\
\text { Index }\end{array}$} & \multicolumn{7}{c}{ Genotypes } \\
\cline { 2 - 8 } & $\mathrm{AA} \alpha$ & $\mathrm{AA} \beta$ & $\mathrm{AB} \alpha$ & $\mathrm{AB} \beta$ & $\mathrm{BB} \alpha$ & $\mathrm{BB} \beta$ & Total \\
\hline $\mathrm{PI}-0$ & 72 & 2 & 0 & 0 & 0 & 0 & 74 \\
$\mathrm{PI}-1$ & 72 & 1 & 0 & 0 & 0 & 0 & 73 \\
$\mathrm{PI}-2$ & 32 & 1 & 2 & 0 & 0 & 0 & 35 \\
$\mathrm{PI}-3$ & 28 & 0 & 2 & 0 & 2 & 2 & 34 \\
$\mathrm{PI}-4$ & 8 & 1 & 2 & 3 & 4 & 11 & 29 \\
$\mathrm{PI}-5$ & 1 & 0 & 6 & 3 & 26 & 54 & 90 \\
$\mathrm{PI}-6$ & 1 & 0 & 7 & 4 & 65 & 168 & 245 \\
\hline Total & 214 & 5 & 19 & 10 & 97 & 235 & 580 \\
\hline
\end{tabular}

in both mitochondria haplotype group (Residual Df $=361$, Deviance $=227.32$, Estimate $=-0.8311, P<0.001)$ and ITS genotype (Residual Df $=361$, Deviance $=461.41$, Estimate $=$ $-0.6814, P<0.001)$. The majority of individuals fell into one of the two groups: (1) individuals of phenotype PI-0 to PI-3 having genotype $\mathrm{AA} \alpha(35.2 \%)$ and (2) those of phenotype $\mathrm{PI}-5$ or PI-6 having genotype $\mathrm{BB} \alpha / \beta$ (53.9\%). Intermediate phenotype and/or other genotypes were observed for $10.9 \%$ of individuals.

\section{Effect(s) of canopy openness and altitude(s)}

Figure 4 shows the relationship of elevation and canopy openness to phenotypic and genotypic characters. Darker forms (i.e., individuals with higher $\mathrm{PI}$ values), the $\mathrm{COI} \beta$ haplotype group, and the ITS2 BB genotype tended to occur in shaded sites across a wide range of altitude, whereas lighter forms, the $\alpha$ haplotype group, and the ITS2 AA genotype tended to occur in relatively open sites over a lower, narrower range of altitude. Table 3 summarizes the results of the generalized liner mixed model (GLMM) with MCMCglmm. After model selection based on DIC, we detected a very large effect of "COP" for all three response variables. On the other hand, there was no significant effect of "Altitude" and "Altitude $\times$ COP". A more extensive analysis only for the effect of altitude based on 49 populations collected in Hokkaido showed a weak effect of altitude on the distribution of these two species for phenotypic index (posterior mean $=0.0014$, pMCMC $=0.178$ ), mitochondria haplotype group (posterior mean $=-0.008, \mathrm{pMCMC}=0.074$ ), and ITS2 genotype (posterior mean $=-0.0001$, pMCMC $=$ $0.174)$

\section{DISCUSSION}

Our results clearly showed that the beetles treated in this study comprise two biological entities (assignable to $P$. quatuordecimpunctata and $P$. japonica), which were differentiated both phenotypically and genotypically. We consider the ITS2 genotypes (AA, AB, BB) fairly reliable characters for distinguishing between these two species. The AA genotype was associated with the mitochondrial $\mathrm{COI} \alpha$ haplotype group (and also with the $\beta$ haplotype group, especially in Honshu) and lighter body color, whereas the BB genotype was associated with the $\mathrm{COI} \alpha / \beta$ haplotype groups and darker body color. Although not all specimens were examined genetically, we conclude that our European specimens are $P$. quatuordecimpunctata. Likewise, Honshu specimens are identifiable with $P$. japonica, except for a single specimen of $P$. quatuordecimpunctata (Sample 86, HNE, Supplementary Table S1 online).

Compared to Honshu, the Hokkaido specimens were diverse, although the presence of the two species is evident (Table 2). Beetles characterized by darker coloration (PI-5, $\mathrm{PI}-6)$ and the $\mathrm{BB} \alpha / \beta$ genotypes are assignable to $P$. quatuordecimpunctata, and those with lighter coloration (PI-0 to $\mathrm{PI}-3)$ and the AA $\alpha$ genotype are assignable to $P$. japonica. Individuals with lighter coloration and the AA $\beta$ genotype may also be $P$. japonica, since this genotype was found in Honshu specimens of putative $P$. japonica. These two "species" constitute $89.8 \%$ of Hokkaido beetles examined both phenotypically and genotypically, and are widely distributed in Hokkaido, frequently in sympatry. Of the 49 Hokkaido sites 

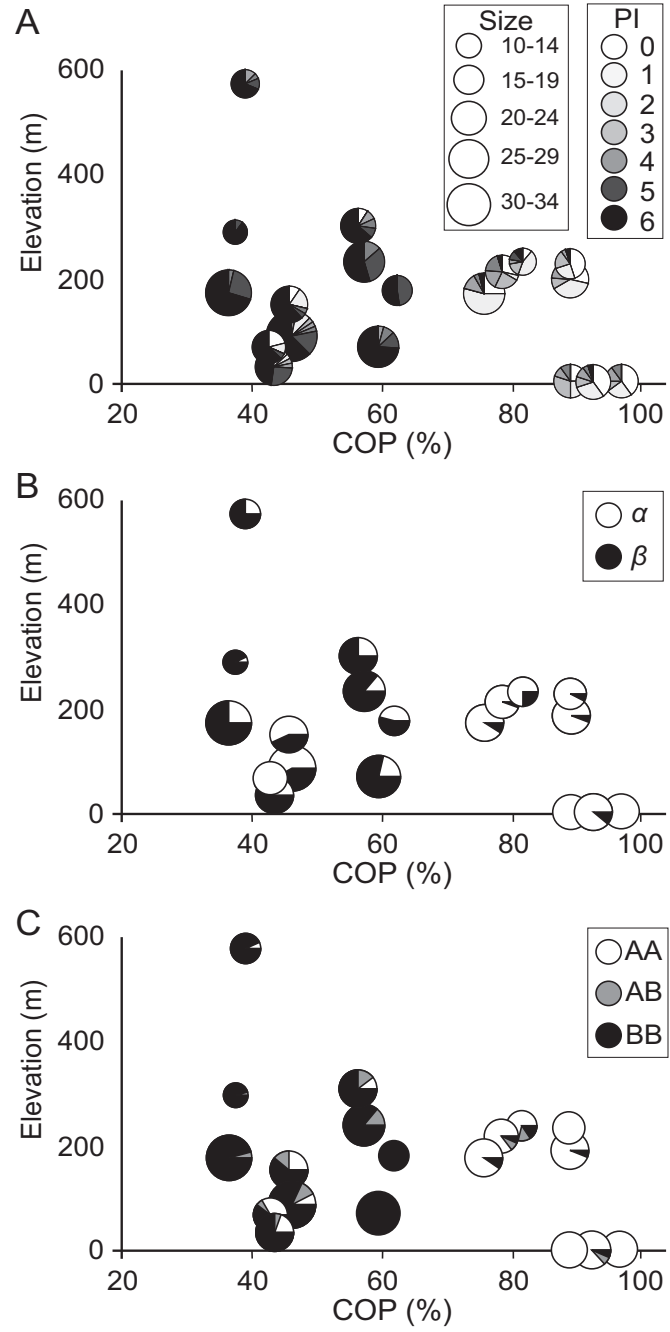

Fig. 4. Distributions of phenotypic index (A), mitochondrial haplotype groups (B), and ITS genotypes (C) for 19 samples in relation to elevation and canopy openness (COP). Phenotypic index values from 0 to 6 correspond to putative $P$. japonica $(0-3)$ and to putative $P$. quatuordecimpunctata $(5,6)$, respectively. The size of each pie graph is proportional to the sample size. The mitochondrial haplotype groups $(\alpha, \beta)$, and ITS genotypes (AA, $\mathrm{AB}, \mathrm{BB})$ are those determined from the haplotype networks (see Fig. 2).

Table 3. Results of the generalized linear mixed model (GLMM) analysis to test the effect of altitude and canopy openness (COP) to phenotypic index, mitochondrial haplotype group, and ITS2 genotype. Factors only selected after model selection are denoted. No significant effect of "Altitude" and "Altitude $\times$ COP" on the three response variables were detected. Statistically significant $P$ values (alpha $=0.05)$ are shown in bold.

\begin{tabular}{lrrrrr}
\hline \multicolumn{1}{c}{ Factor } & $\begin{array}{c}\text { Posterior } \\
\text { mean }\end{array}$ & $\begin{array}{c}\text { Upper } \\
95 \% \mathrm{Cl}\end{array}$ & $\begin{array}{c}\text { Lower } \\
95 \% \mathrm{Cl}\end{array}$ & $\begin{array}{c}\text { Effective } \\
\text { sample sizes }\end{array}$ & $P$-value \\
\hline $\begin{array}{l}\text { Total phenotypic index } \\
\quad \text { Intercept }\end{array}$ & 2.837 & 2.434 & 3.316 & 241.9 & $<\mathbf{0 . 0 0 1}$ \\
$\quad$ COP & -0.026 & -0.033 & -0.02 & 183.3 & $<\mathbf{0 . 0 0 1}$ \\
$\begin{array}{l}\text { Mitochondrial haplotype group } \\
\text { Intercept }\end{array}$ & -23.485 & -39.406 & -4.527 & 8.144 & $<\mathbf{0 . 0 0 1}$ \\
COP & 0.426 & 0.08 & 0.695 & 7.164 & $<\mathbf{0 . 0 0 1}$ \\
ITS genotype & & & & & \\
$\quad$ Intercept & -0.636 & -1.007 & -0.181 & 12.44 & $\mathbf{0 . 0 0 8}$ \\
COP & 0.019 & 0.013 & 0.024 & 18.39 & $<\mathbf{0 . 0 0 1}$ \\
\hline
\end{tabular}

for which both phenotypic data and genotypic data were available, " $P$. japonica" and " $P$. quatuordecimpunctata" as defined here were collected from 24 sites and 40 sites, respectively, with co-occurrence at 15 sites (Fig. 5).

A low proportion (10.2\%) of individuals were not assigned into the two groups above. This may simply reflect partly overlapping ranges of phenotypic variation for $P$. japonica and $P$. quatuordecimpunctata. However, variation in the DNA markers raises the alternative possibility that these intermediate individuals represent natural hybrids between the two species. Individuals having the $A B$ genotype associated with the $\alpha$ or $\beta$ haplotype group and moderate to dark body color are particularly noteworthy. The composition of the Hokkaido beetles summarized in Table 2 is explained well by the secondary contact of two phenotypically and genetically divergent groups, $P$. quatuordecimpunctata and $P$. japonica, followed by limited hybridization. In addition, it is apparent from Table 2 that the individuals of phenotypes $\mathrm{PI}-0$ to $\mathrm{PI}-3$ were mainly associated with the $\alpha$ haplotype group of $\mathrm{COI}$, while those of phenotypes $\mathrm{PI}-5$ and PI- 6 with both the $\alpha$ and $\beta$ groups. These results seem to corroborate with the results of laboratory mate-choice tests reported by Sajima and Sasaji (1988), in which males of $P$. japonica were choosier and less frequently mated with heterospecific females than those of $P$. quatuordecimpunctata. Although our analyses are not conclusive, we speculate that natural hybridization occurs between the two Propylea species in Hokkaido. Further analysis, including that in populations with high genetic variation, is needed to elucidate detailed historical process of speciation and gene flow between these two species.

Sasaji et al. (1975) concluded that there is a difference in altitudinal distribution between $P$. japonica and $P$. quatuordecimpunctata, with the former tending to live at lower altitudes than the latter. Our results certainly corroborate this. Although both the lighter and darker forms occurred across a wide range of altitudes, the lighter forms were found mainly at less than $300 \mathrm{~m}$ alt., whereas the darker forms commonly occurred from the lowlands up to $600 \mathrm{~m}$ or more (Supplementary Table S1 online, Fig. 4, Fig. 5). However, our detailed analysis strongly suggests that canopy openness plays a more important role than altitude to determine the distribution of the two species (Fig. 4, Table 3). Individuals with lighter phenotypes, mitochondrial $\alpha$ haplotypes, and the ITS2 AA genotypes (representing putative $P$. japonica) were found in relatively open places, whereas those with darker phenotypes, $\beta$ haplotypes, and BB genotypes (putative $P$. quatuordecimpunctata) were found in shaded places (Fig. 4). The GLMM analysis showed that the distribution of the phenotypic groups (PI-0 to 6) and the mitochondrial $\mathrm{COI}$ haplotype groups, and ITS2 genotypes were significantly affected by only canopy openness. In the areas surveyed in this study, open habitats such as rural areas, grassland, and disturbed areas are more common at lower altitudes, whereas woodlands are more common at intermediate to higher altitudes. The GLMM 


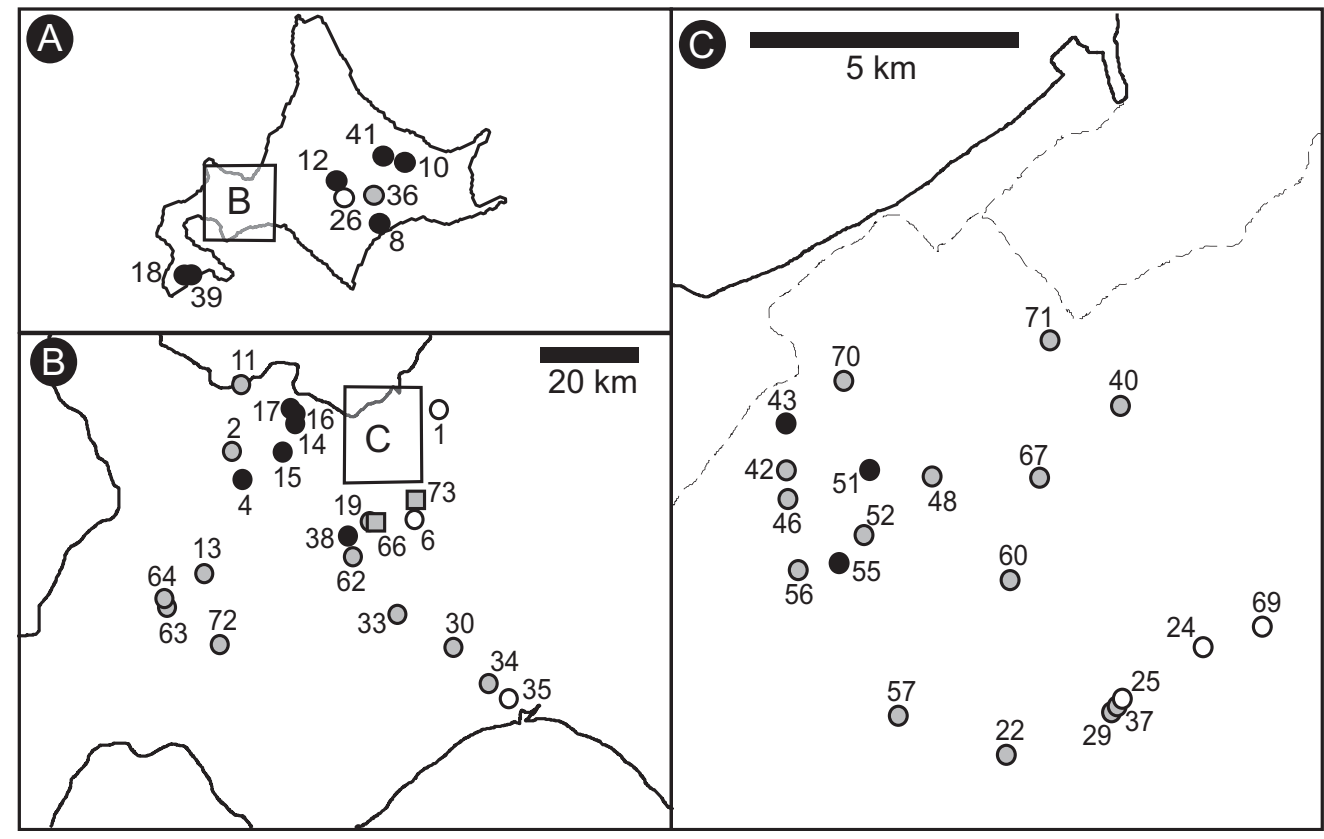

Fig. 5. Distribution of " $P$. japonica", " $P$. quatuordecimpunctata", and their hybrid individuals identified based on both phenotypes and genotypes. Filled circles represent populations in which only " $P$. japonica" was found. Open circles represent populations that were composed of only " $P$. quatuordecimpunctata". Gray filled circles represent populations including putative hybrid individual together with " $P$. japonica" and/ or "P. quatuordecimpunctata". Gray filled squares represent populations that included both " $P$. japonica" and "P. quatuordecimpunctata" but no hybrid individual.

further showed that altitude has small effect on the distribution of the Propylea beetles in Hokkaido. Consequently, the observed altitudinal difference between the two Propylea species may be a consequence of this habitat difference.

The primary causes of the altitudinal difference and the habitat difference is unknown. Some studies have reported a certain degree of habitat preference in $P$. quatuordecimpunctata (Honěk, 1985; Hemptinne, 1988). However, how such habitat preference relates to the observed habitat difference of the present species pair is unknown. One possibility is a physiological difference, with adaptation of $P$. japonica to slightly warmer environments than $P$. quatuordecimpunctata. This is consistent with the global distribution, altitudinal difference, and habitat difference of these two Propylea species. In addition, difference in habitats can be a consequence of prey difference. Indeed, some studies have reported that Propylea beetles exhibit preference to and/or better performance on some prey species over others under laboratory conditions (Kalushkov and Hodek, 2005; Hodek and Evans, 2012; Keshavarz et al., 2015). Such association with particular prey species, if any, may play a role for the observed habitat difference in the two Propylea species. Careful comparative studies are needed to test the validity of these hypotheses.

As described above, some degree of sexual isolation has also been detected between the two Propylea species under laboratory conditions (Sajima and Sasaji, 1988). Habitat differences may act as another reproductive barrier that reduces encounters and occasional hybridization between the two species. However, our results also suggest that pre-mating isolation between $P$. quatuordecimpunctata and $P$. japonica is incomplete. Some sorts of postmating isolating barriers must play a role in preventing the two species from merging in the wild, counteracting occasional hybridization. Sasaji et al. (1975) reported that, in laboratory, populations of offspring from $F_{1}$ hybrids between the two species died off within a few generations due to a decrease in the hatching rate of eggs and/ or increased larval mortality. These post-mating barriers may also function in the wild. However, the results of the crossing experiments by Sasaji et al. (1975) did not completely rule out the possibility of inbreeding effects after interspecific crossing (cf. Morjan et al., 1999). A thorough follow-up study is necessary in order to confirm the results of the pioneer studies conducted

by Sasaji and his team.

Thus, it seems that there is a wide range of Propylea hybrid zone in Hokkaido. This system thus provides an excellent opportunity for studying various evolutionary issues, in particular those concerning speciation, as briefly discussed above. It should be clarified how extensive the hybrid zone is in the area outside Hokkaido, as the ranges of these two species overlap in Honshu, Japan, and probably so in the northeastern part of continental Asia. It also remains to be clarified how long the sympatry of " $P$. japonica" and " $P$. quatuordecimpunctata" has lasted in eastern Asia. The divergence time between the two haplotype groups of $\mathrm{COI}$ was estimated to be 1.6 Mya. Although this figure does not directly show the time of speciation of the two species, one likely explanation is that the two species diverged in the later period of Pleistocene under allopatric conditions (one in the western part of the Palearctic region and the other in the eastern part) and then met in the Far East as a consequence of range expansion due to subsequent geo-climatic changes. A more intensive molecular analysis of population structures with diverse samples from the overall distribution ranges of the two species will deepen the understanding of the evolutionary dynamics of the Propylea hybrid zone.

\section{ACKNOWLEDGMENTS}

We dedicate this paper to the late Dr. Hiroyuki Sasaji, who discovered the Japanese Propylea problem and, along with his students, conducted many pioneering studies. We thank R. Masuda and $\mathrm{H}$. Kajihara for comments on an early version of the manuscript; Y. Tada, N. Ito, and T. Hino for technical advice on experiments and data analysis; and N. Fujiyama, B. Novkovic, Y. Tada, 
S. Kikuta, A. Togashi, T. Kohyama, N. Ito, K. Furukawa, I. Uematsu, and S. Yamasaki for samples and field assistance.

\section{REFERENCES}

Ayres DL, Darling A, Zwickl DJ, Beerli P, Holder MT, Lewis PO, et al. (2011) BEAGLE: an application programming interface and high-performance computing library for statistical phylogenetics. Syst Biol 61: 170-173

Bandelt H, Forster P, Röhl A (1999) Median-joining networks for inferring intraspecific phylogenies. Mol Biol Evol 16: 37-48

Boom R, Sol CJ, Salimans MM, Jansen CL, Wertheim-van Dillen PM, et al. (1990) Rapid and simple method for purification of nucleic acids. J Clin Microbiol 28: 495-503

Coyne JA, Orr HA (1998) The evolutionary genetics of speciation. Philos Trans R Soc London [Biol] 353: 287-305

Coyne JA, Orr HA (2004) Speciation. Sinauer Associates, Sunderland

Crow KD, Munehara H, Kanamoto Z, Balanov A, Antonenko D, Bernardi G (2007) Maintenance of species boundaries despite rampant hybridization between three species of reef fishes (Hexagrammidae): implications for the role of selection. Bio $\mathrm{J}$ Linnean Soc 91: 135-147

de Casas RR, Cano E, Balaguer L, Perez-Corona E, Manrique E, Garcia-Verdugo C, Vargas P (2007) Taxonomic identity of Quercus coccifera $\mathrm{L}$. in the Iberian Peninsula is maintained in spite of widespread hybridisation, as revealed by morphological, ISSR and ITS sequence data. Flora 202: 488-499

Drummond AJ, Suchard MA, Xie D, Rambaut A (2012) Bayesian phylogenetics with BEAUti and the BEAST 1.7. Mol Biol Evol 29: 1969-1973

Futuyma DJ (2013) Evolution. 3rd ed, Sinauer Associates, Sunderland

Hedges SB, Marin J, Suleski M, Paymer M, Kumar S (2015) Tree of life reveals clock-like speciation and diversification. Mol Biol Evol 32: 835-845

Hemptinne JL (1988) Ecological requirements for hibernating Propylea quatuordecimpunctata (L.) and Coccinella septempunctata (Col.: Coccinellidae). Entomophaga 33: 505-515

Hodek I, Evans EW (2012) Food relationships. In "Ecology and Behavior of the Ladybird Beetles (Coccinellidae)" Ed by I Hodek, HF van Emden, A Honěk, Wiley-Blackwell, Oxford, pp 141-274

Hodek I, van Emden HF, Honěk A (2012) Ecology and Behavior of the Ladybird Beetles (Coccinellidae). Wiley-Blackwell, Oxford

Honěk A (1985) Habitat preferences of aphidophagous coccinellids (Coleoptera). Entomophaga 30: 253-264

Honěk A (2012) Distribution and habitats. In "Ecology and Behavior of the Ladybird Beetles (Coccinellidae)" Ed by I Hodek, HF van Emden, A Honěk, Wiley-Blackwell, Oxford, pp 110-140

Hukushima S, Komada N (1971) Bionomics of Propylaea japonica Thunberg (Coleoptera: Coccinellidae). Res Bull Agric Gifu Univ 31: 137-145

Kalushkov P, Hodek I (2005) The effect of six species of aphids on some life history parameters of the ladybird Propylea quatuordecimpunctata (Coleoptera: Coccinellidae). Eur J Entomol 102: 449-452

Kawauchi SE (1997) Life histories of Coccinella septempunctata brucki, Propylea japonica and Scymnus hoffmanni (Col., Coccinellidae) in Japan. Entomophaga 42: 41-47

Keshavarz M, Seiedy M, Allahyari H (2015) Preference of two populations of Propylea quatuordecimpunctata (Coleoptera:
Coccinellidae) for Aphis fabae and Aphis gossypii (Homoptera: Aphididae). Eur J Entomol 112: 560-563

Levin D (2000) The Origin, Expansion and Demise of Plant Species. Oxford University Press, New York

Librado P, Rozas J (2009) DnaSP v5: a software for comprehensive analysis of DNA polymorphism data. Bioinformatics 25: 14511452

Lunt DH, Zhang D-X, Szymura JM, Hewltt OM (1996) The insect cytochrome oxidase I gene: evolutionary patterns and conserved primers for phylogenetic studies. Insect Mol Biol 5: 153165

Morjan WE, Obrycki JJ, Krafsur ES (1999) Inbreeding effects on Propylea quatuordecimpunctata (Coleoptera: Coccinellidae). Ann Entomol Soc Am 92: 260-268

Nylander JAA (2004) MrModeltest v2. https://github.com/nylander/ MrModeltest2

Papadopoulou A, Anastasiou I, Vogler AP (2010) Revisiting the insect mitochondrial molecular clock: The mid-aegean trench calibration. Mol Biol Evol 27: 1659-1672

Pervez A, Omkar (2011) Ecology of aphidophagous ladybird Propylea species: A review. J Asia-Pac Entomol 14: 357-365

R Developmental Core Team (2014) R: A language and environment for statistical computing. http://www.R-project.org/

Rambaut A, Suchard MA, Xie D, Drummond AJ (2014) Tracer v1.6. http://beast.bio.ed.ac.uk/Tracer

Sajima H, Sasaji H (1988) Preferential matings in two sibling species of Propylea japonica complex (Coleoptera: Coccinellidae). Entomol J Fukui 2: 17-22 (in Japanese with English synopsis.)

Sasaji H (1998) Natural History of the Ladybirds. University of Tokyo Press, Tokyo (in Japanese)

Sasaji H, Yahara R, Saito M (1975) Reproductive isolation and species specificity in two ladybirds of the genus Propylea (Coleoptera). Mem Fac Edu Fukui Univ II 25: 13-34

Swofford DL (2003) PAUP*. Phylogenetic Analysis Using Parsimony ( ${ }^{*}$ and Other Methods). Version 4. Sinauer Associates, Sunderland

Takenaka A (2009) CanopOn2 ver. 2.03. http://takenaka-akio.org/ etc/canopon2/index.html

Tamura K, Peterson D, Peterson N, Stecher G, Nei M, Kumar S (2011) MEGA5: molecular evolutionary genetics analysis using maximum likelihood, evolutionary distance, and maximum parsimony methods. Mol Biol Evol 28: 2731-2739

Thompson JD, Higgins DG, Gibson TJ (1994) CLUSTAL W: improving the sensitivity of progressive multiple sequence alignment through sequence weighting, position-specific gap penalties and weight matrix choice. Nucleic Acids Res 22: 4673-4680

White TJ, Bruns T, Lee S, Taylor J (1990) Amplification and direct sequencing of fungal ribosomal RNA genes for phylogenetics. In "PCR Protocols: a Guide to Methods and Applications" Ed by MA Innis, DH Gelfand, JJ Sninsky, TJ White, Academic Press, New York, pp 315-322

Wu C-I (2001) The genic view of the process of speciation. J Evol Biol 14: 851-865

Yatabe Y, Kane NC, Scotti-Saintagne C, Rieseberg LH (2007) Rampant gene exchange across a strong reproductive barrier between the annual sunflowers, Helianthus annuus and $H$. petiolaris. Genetics 175: 1883-1893

(Received April 7, 2016 / Accepted July 8, 2016) 